\title{
The Thermal Performance of Vernacular Houses as An Identity of Kurdish Traditional Architecture
}

\author{
Binaee Yaseen Raof \\ Department of City Planning/ Technical \\ College of Engineering \\ Sulaimani Polytechnic University \\ Sulaimani, Iraq \\ binaee.yaseen@spu.edu.iq
}

\author{
Sara Dhiaadin Bahaadin \\ Department of City Planning/ Technical \\ College of Engineering \\ Sulaimani Polytechnic University \\ Sulaimani, Iraq \\ sara.bahaadin@spu.edu.iq
}

\author{
Hoshyar Qadir Rasul \\ Department of City Planning/ Technical \\ College of Engineering \\ Sulaimani Polytechnic University \\ Sulaimani, Iraq \\ hoshyar.rasul@spu.edu.iq
}

\begin{tabular}{l}
\hline Article Info \\
\hline Volume $5-$ Issue 1 - \\
June 2020 \\
DOI: \\
10.24017/science.2020.1.17 \\
Article history: \\
Received:10 April 2020 \\
Accepted: 14 June 2020 \\
\hline
\end{tabular}

Keywords:

Vernacular architecture, courtyard, climatic factor, Computer simulation, thermal comfort, thermal performance.

\begin{abstract}
Nature in general and especially climate, play a decisive role in defining the architecture of a place or people over time. Therefore, it is more convenient to look at architecture as a mirror reflects people's adaptation and behavior to the environment over time. Because of mainstream design with lowtech conditions, the climate is the predominant power that characterizes the building types. In this manner, as long as the climate differs from one place to another, the vernacular architecture is going to be differs as well, due to the environmental conditions. Traditional houses were adopted to meet the basic psychological and physiological needs of man through the most rational elements, such as building floor plans (spatial organization), materials, shapes, details and floor effects in various ranges. As a result, these architectural features marked the identity features of local architecture in the city. For this reason, the paper focuses on testing the thermal performance of some types of vernacular houses commonly used in the city of Sulaimani, especially in the traditional zone of the city. To achieve the research objectives, the study followed experimental analytical methodology, using outputs of the most appropriate software (Design Builder) to test the performance of three common types of local traditional houses (single and double floors). It appears that the type $L$ with single floor is the
\end{abstract}


most efficient, but the $U$ shape with single floor recorded the highest number of days throughout the year when energy was needed.

\section{INTRODUCTION}

The structure and the form of residential units are formed due to the cultural condition, which reflects socio-cultural components, (e.g. religion). The structure of the family and society are additional significant parts of culture that influence building and built up environment. [1]. Consequently, it can be said that, the physical environment is reflection of these socio-spatial associations and the climatic condition as well, which try to make the private environment of family life.

Traditional house is viewed as an environmental and social responsive architecture, coming from the immersive quantities of progenitor's core through hundreds of years of inhabitation. Collected over long time, climatic reaction obligations suggested in traditional houses are the most significant encounters demonstrating the characters of eco-friendly conducts of man.

Coch states that the environmental factors are crucial among the other driven powers, where socio-culture, economy, spiritual or material assets and valuable method, etc., creating differences in architectural forms. [2]. The absence of clear view related to which of traditional dwelling types poses the most thermal performance, and considered as the most convenience type environmentally, is formed the problem research. This absence is due to existing of many types of traditional dwellings in the city, aiming to find out the basic architectural element, which is used in this preferred type that acted on dwellings to be ecofriendly, and close to the thermal comfort.

The entire procedure aimed to recognize some traits of Kurdish architecture identity. Finally, to recommend experimentally evolving in to the future design of houses in the city.

\section{LITERATURE REVIEW}

\subsection{Vernacular Architecture}

Vernacular architecture has many definitions as its components themselves. Starting with Paul Oliver who says: "Vernacular architecture is a field of architectural theory that examines the structures created by empirical builders without the intervention of professional architects. [3] As called by Bernard Rudofsky " architecture without architects ", has generated from age to age through (trial and error) procedure, to address their issues and values. Since the absolute starting point of architecture, had been depended on knowledge and experience, traditional architecture has attempted to accomplish convenience among environment and buildings. [4]. In the case of vernacular architecture with a low-tech technique and available technology, the environment becomes the crucial force determining the pattern of its architecture. Thus, as long as the macro-climate changes from one place to another, the vernacular architecture also seems to be varied, due to the environmental circumstances.

The achievement of several objectives, such as thermal performance, which has been more and more adopted with design techniques related to energy considerations, and the latter formed the basics of bioclimatic concepts. The integration of space organization concepts harmonizes with natural heating, cooling, ventilation and lighting techniques, and the application of the passive impact of natural material with environmental solutions and their techniques. 


\subsection{Built environment and human comfort}

Man-made environment has effective influences on human's gratification and well-being. Building's reaction to occupants' physical and mental needs is fundamental to give them a feeling of self-esteem, wellbeing, and protection. Despite all these, it is important to get solid situation, in order to please, elevate, and unwind or furnish contact with nature. [5].

To achieve the real satisfaction, the human body should therefore be at a level of comfort, that depends on the adaptation of the inside to the outside environment.

Accordingly, the environment has the highest crucial influences that can affect human comfort. Regarding the differences in the climate components in different places of the world, each place therefore needs its specific design and techniques in construction approaches or methods, that capable to provide human comfort.

\subsubsection{Climate comfort in Architecture}

"One of the effective factors in the human life, health and comfort is climate comfort. A human being directly and indirectly has been affected by this condition" [6]

Gioni presented a bioclimatic chart of building and Elgi presented humidity and heating conditions about human needs and climate design then drew the bioclimatic chart [7]. Ghobadian and Mahdavi, (2013) had presented different mechanisms for analyzing thermal comfort and climate control techniques. Saligheh, (2004) has presented climatic design models convenience with the regional climate for the improvement of thermal comfort and raising the related indexes. Razjooyan, (1988) has tried to analyze the effective factors of comfort by publishing his valuable book, entitled "Comfort by Architecture Compatible with Climate". [8]

Depending the above-mentioned researches, the man-made environment is to a large extent linked to the climate conditions. Furthermore, there are different classifications of architecture depending on the climate traits, such as cold, temperate, warm-humid and hot-dry climate. We can use these classifications to achieve a comfort level when the purpose is to build in different climate zones.

\subsection{The thermal performance of buildings}

The precision of any thermal reproduction has direct impacts on the thermal performance of any building, and the required plan of thermal and cooling loads to support thermal comfort. Numerous factors influence the thermal performance of a building, and both independent and interconnected factors impact the thermal performance, with some having a more prominent effect than others [9].

Because of the dynamic traits of climate conditions, these factors are continually changing, which makes it hard to precisely predict the thermal energy performance [10], [11].

To get an exact appraisal of the thermal performance of a building, a record should consequently, be taken as a whole system, under the conditions of external variables. [11].

\subsection{Traditional Housing (techniques and solutions)}

In the traditional dwelling patterns, there is the high-level harmony between buildings, place and geography. Moreover, the utilization of available materials and forms along with the local culture makes a sustain agreement and uprightness between the buildings. As it were, the traditional dwelling has just accomplished the high degree solutions environmentally in terms of the thermal comfort; furthermore, the current environmental dialogue has been consolidated into the typology of traditional housing.

Techniques of construction, and all related issues of vernacular architecture are increasingly founded on accumulated knowledge based on (trial and error) rather than systematic practices. Vernacular buildings pose a decent answer for the climatic requirements, and there are enormous ways to resolve the similar or equivalent climatic problem [12]. It suggests a congruity between buildings, inhabitants, and surrounding. These types of structure developed historically to mirror the ecological, social and cultural setting in which they exist.[2].

Various common techniques have been used, which generally reflect their rational solutions to the severity of the weather and are considered to be the thermal performance of these 
traditional buildings, such as (Clay bricks - low heat radiation, low cost, availability. Thick walls - high insulation, small windows not facing the sun, Roof - windbreak for cooling the interior. Mashrabyia - shades - limiting glare from light, and courtyard with partial greening to shield dust in the prevailing wind ...)

\subsection{Courtyard Houses as the basic type of traditional architecture}

The history of using courtyards could be returned to 5000 years ago in Egypt. It is one of the traditional architectural solutions, which are used continuously in different climate zones and cultures along thousands of years [13].

One of the main reasons for using courtyard is its performance toward the environmental effects. So, It has been used in different climates as a socio-spatial, climatic and design modifier, which has led to a more successful solution through ancient periods until today. Fig. (1)

It can be a sunscreen, natural ventilation and a natural evaporative cooling element using vegetation and fountains. Moreover, the high walls around the courtyard can increase the shaded area, which reduces the temperature of the ground surface. In this process, the volume, shape and ratio hold the crucial influences.

The courtyard tends to vary in size and shape depending on its geographical location and climate. It can be completely closed or semi-closed. In other words, it can be square (closed on all sides), U-shaped (closed on 3 sides with the fourth side open), L-shaped (open on 2 sides and closed on the other 2 sides) and I-shaped (open on 3 sides and closed on the other side). Each shape has its thermal performance, which is different from the other.
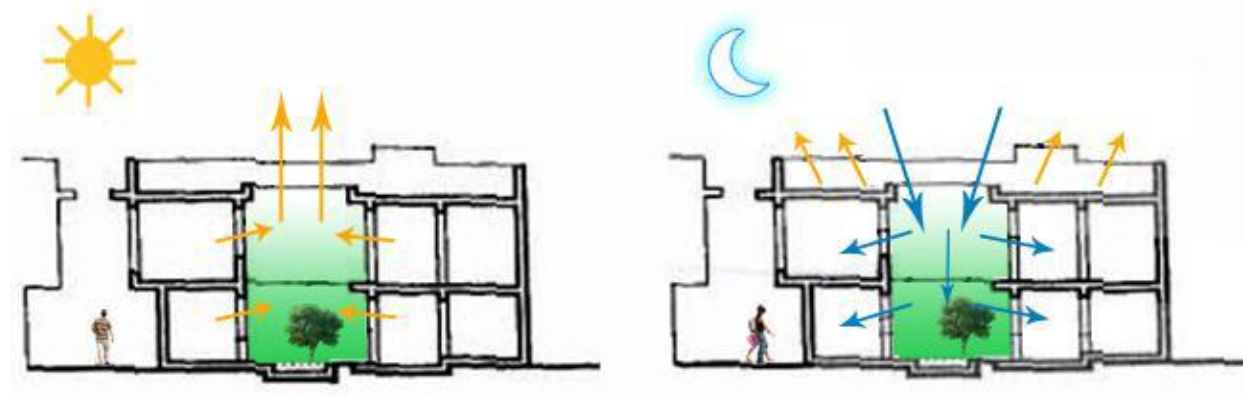

Figure 1: Courtyard as the most climatic modifier element [13].

\section{METHODS AND MATERIALS}

Bioclimatic study of Sulaymaniyah city is crucial to investigate the differences in climatic comfort of different types of dwellings - caused by the shape of courtyards - either to determine the influence of building layout on thermal comfort within traditional residential buildings or to determine their climatic conformity during hot and cold seasons. This was done with the help of simulation software (DesignBuilder).

The process carried out to achieve the objective of the study, using the following analytical methodology:

A. The climatic and bioclimatic analysis of Sulaymaniyah city.

B. Analysis of the selected types of traditional residential models.

C. Simulation for the used types by using the Sulaymaniyah climatic data.

D. Analyzing the software results for indoor temperatures and relative humidity in the hot and cold periods for the selected residential types.

\subsection{The climatic analysis of Sulaymaniyah City}

The city of Sulaymaniyah is located in the North East part of Iraq in a mountainous area of the country near the Iran-Iraq border. Figure (2). Its latitude is $35^{\circ} 33^{\prime} 53.86^{\prime \prime}$ north and $45^{\circ} 25^{\prime} 58.44^{\prime \prime}$ east, and its altitude above sea level is $847 \mathrm{~m}$. [14] 


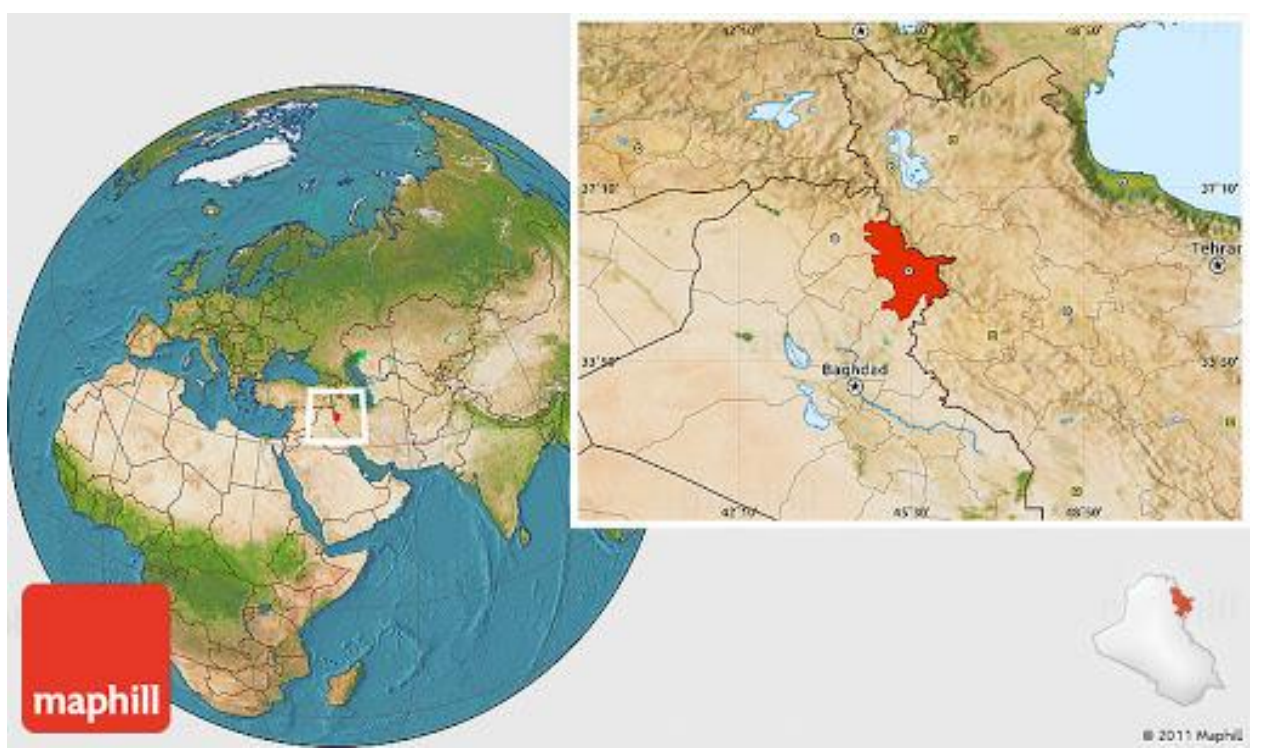

Figure 2: The Map of Iraq and location of Sulaymaniyah city according to it (maphill, 2011).

The climatic analysis is carried out using data collected based on EPW (energy plus weather) file of the Sulaymaniyah weather. These were reproduced by the Climate Consultant 6.0 software.

Below is an analytical overview of the data:

\subsubsection{Solar brightness and radiation:}

Direct normal solar radiation in the city reaches its minimum in November and February, which is about $150 \mathrm{Wh} / \mathrm{sqm}$, while the maximum radiation reaches almost $720 \mathrm{Wh} / \mathrm{sqm}$ in August (Figure 3).

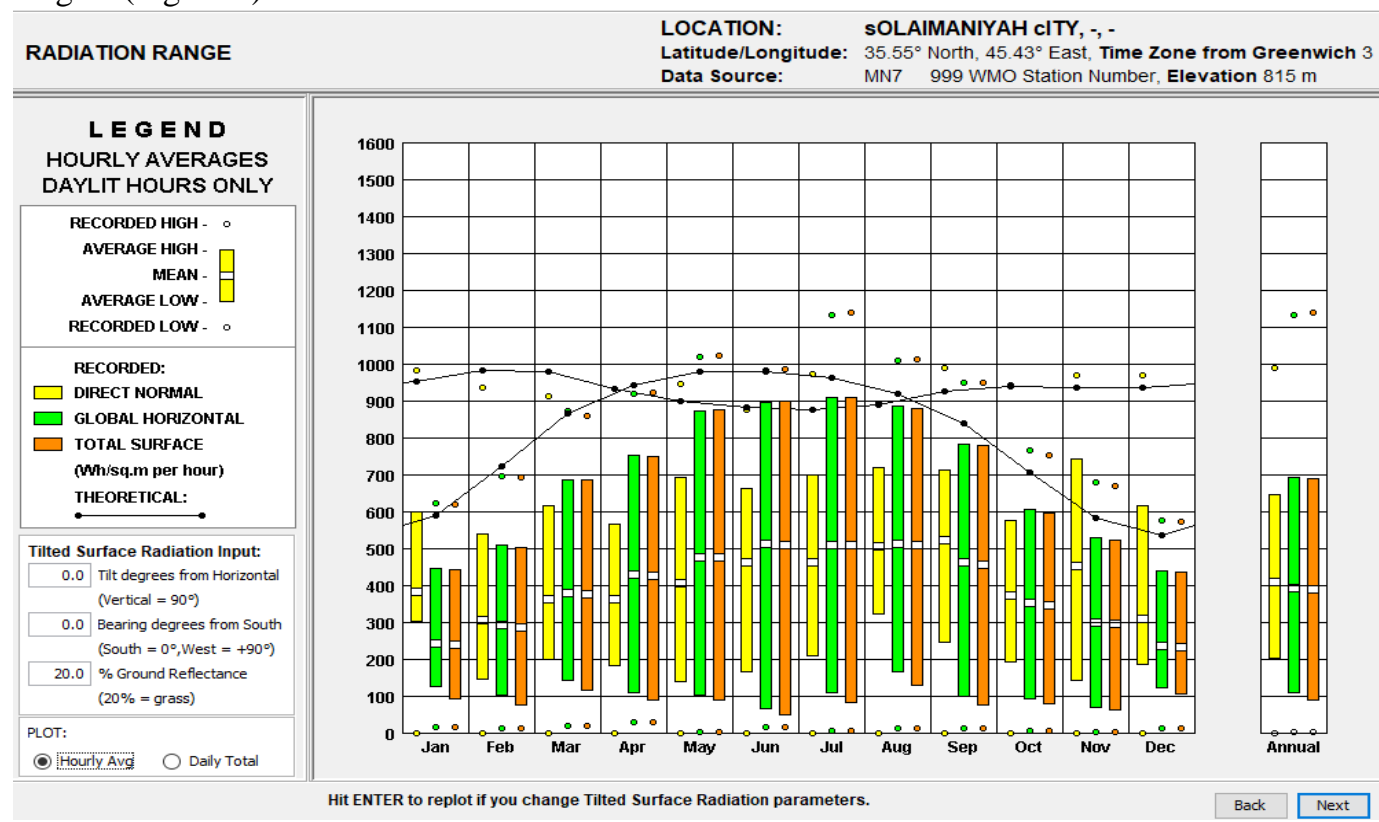

Figure 3: Radiation range, based on Sulaymaniyah weather file data. Reproduced from Climate consultant 6.0 software [19]. 


\subsubsection{Air temperature}

As a result of differences in solar radiation, air temperature is considered a climatic variable that varies greatly from region to region. In the city of Sulaymaniyah there is both a dry and rainy season; the dry season is from April to October, while the rainy season is from November to March. The average monthly temperature is between $8^{\circ} \mathrm{C}$ and $22^{\circ} \mathrm{C}$, with an average annual temperature of $16^{\circ} \mathrm{C}$. The hottest months are July and August. Figure (4) shows that the maximum temperature in January is $13^{\circ} \mathrm{C}$, and the minimum is almost $-14^{\circ} \mathrm{C}$. Also, the maximum temperature in July is $42^{\circ} \mathrm{C}$, with a minimum of $17^{\circ} \mathrm{C}$ (during the night time). Furthermore, the average maximum temperature in July is $37^{\circ} \mathrm{C}$, with almost $21^{\circ} \mathrm{C}$ the average minimum temperature (during the night time) [19].

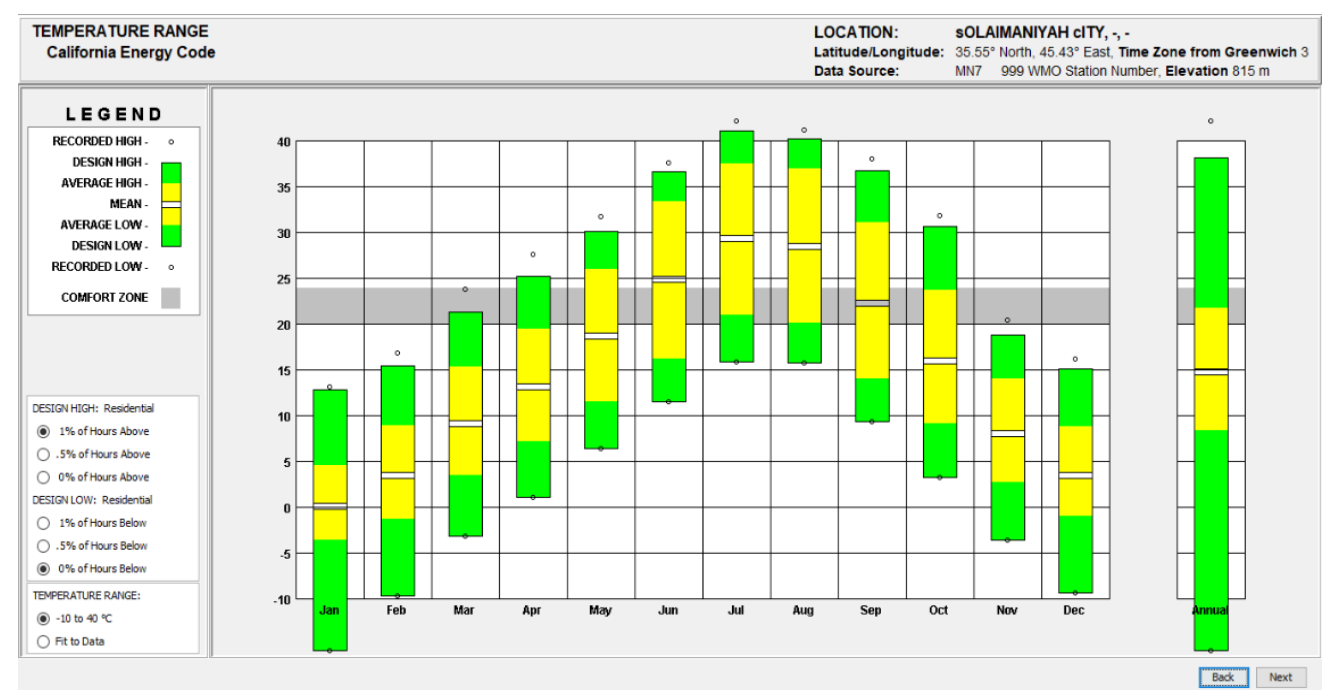

Figure 4: Sulaymaniyah air temperature data all over the year, based on Sulaymaniyah's weather file data. Reproduced from Climate consultant 6.0 software [19].

\subsubsection{Relative Humidity}

Relative humidity is another climatic variable that affects indoor thermal comfort. Relative humidity is generally low in the city of Sulaymaniyah, averaging 47.4\% annually. In August it drops to $23 \%$, while in January it averages $75 \%$. Figure (5) 


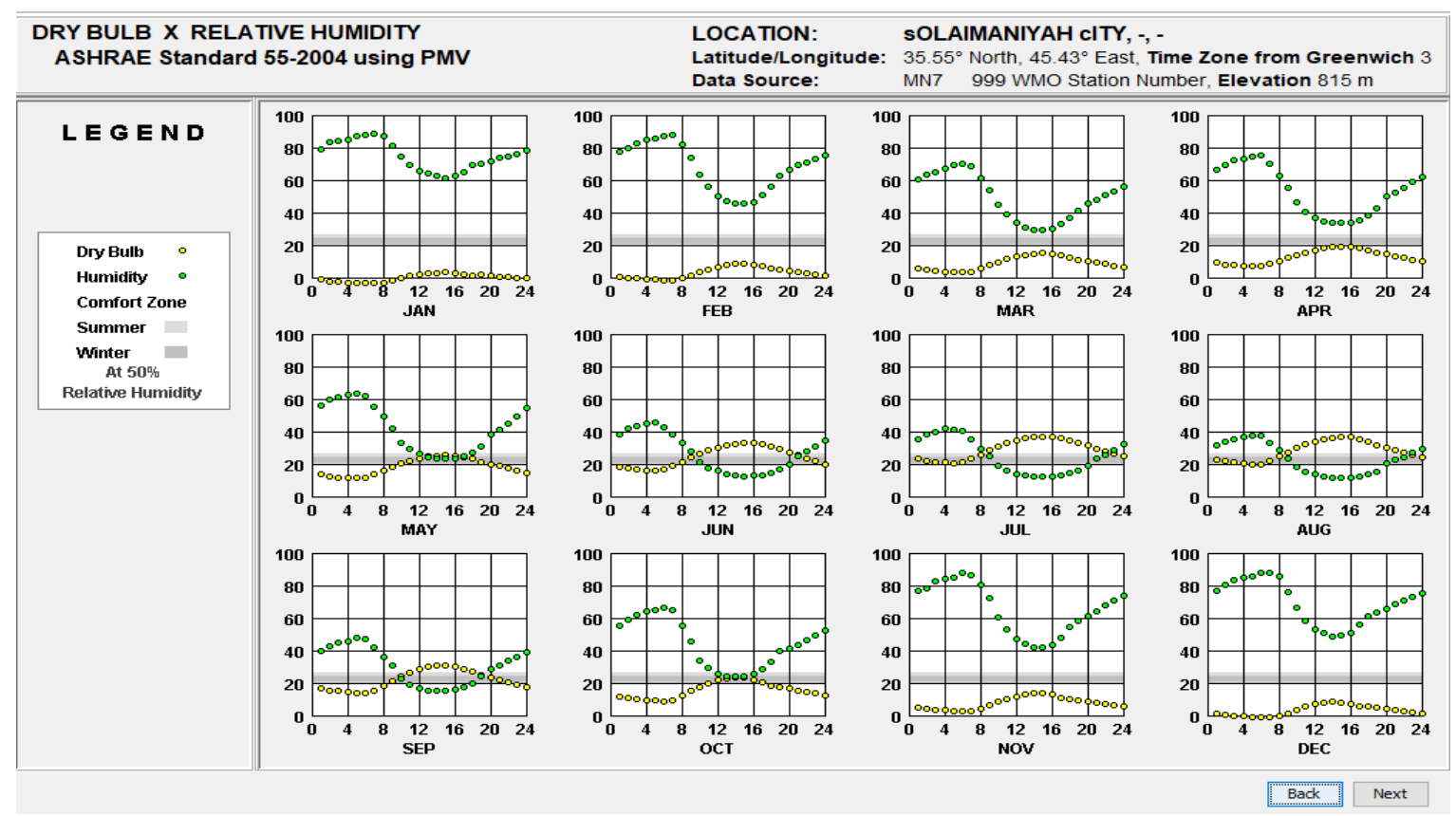

Figure 5: Max, Min, and average relative humidity of Sulaymaniyah city based on Sulaymaniyah's weather file data. Reproduced from Climate consultant 6.0 software [19].

\subsection{A detailed study of the selected residential models}

To fill the knowledge gap identified above, the (DesignBuilder program) has used energy simulation software. DesignBuilder is a graphical visualization interface of a dynamic thermal simulation machine called Energy Plus, developed by the U.S. Department of Energy (DOE). These software records daily and monthly simulations, which in our case were performed for three selected types(models) of traditional houses, built in the 1920s in the city of Sulaimani. The main climate variables considered are outdoor air temperature and humidity. Regarding the wind effect on thermal comfort, the DesignBuilder software is considering the natural ventilation is on in all the models therefore the effect of natural wind is calculated within the results.

The types were selected according to their floor plan layout, the courtyard forms and the number of floors. In addition, the occupancy density is 0.0229 people $/ \mathrm{m} 2$ [20]. This is set from the simulation software DesignBuilder defaults (see index). Models descriptions are as follows:

- I-shaped courtyard housing unit (Single and Double Floors): Single Floor Type of unit consists of (6 rooms) with a large courtyard. However, 2 floors of the I-type, which is most common within the traditional zone in the city of Sulaimani. Its ground floor has the same design as (Single Floor), but its first floor consists of (4 rooms) with a space designed as a covered hall with three walls (between two rooms), and the fourth is completely open to the courtyard and is called (Ewan type) See (Table 1).

- L-shaped courtyard housing unit (Single and Double Floors): in Sulaimani urban housing context in the past this form of residential unit was highly used $(1$ and 2 floors),since it was high in privacy and practical in terms of building and managing, and the plans show that the interiors for this type are more private compared to (I shape) and the area of the courtyard is smaller.

- U-shaped courtyard housing unit (single and Double Floors): These types of houses have many rooms comparing to other chosen houses (I and L shapes). 
The simulation process had been carried out separately for each type, daily and monthly measurements of indoor air temperature are recorded with climate data through detail study of the DesignBuilder simulation software.

Table 1: Selected prototypes of traditional houses configuration (plan-s- and courtyard shapes)/ - Case
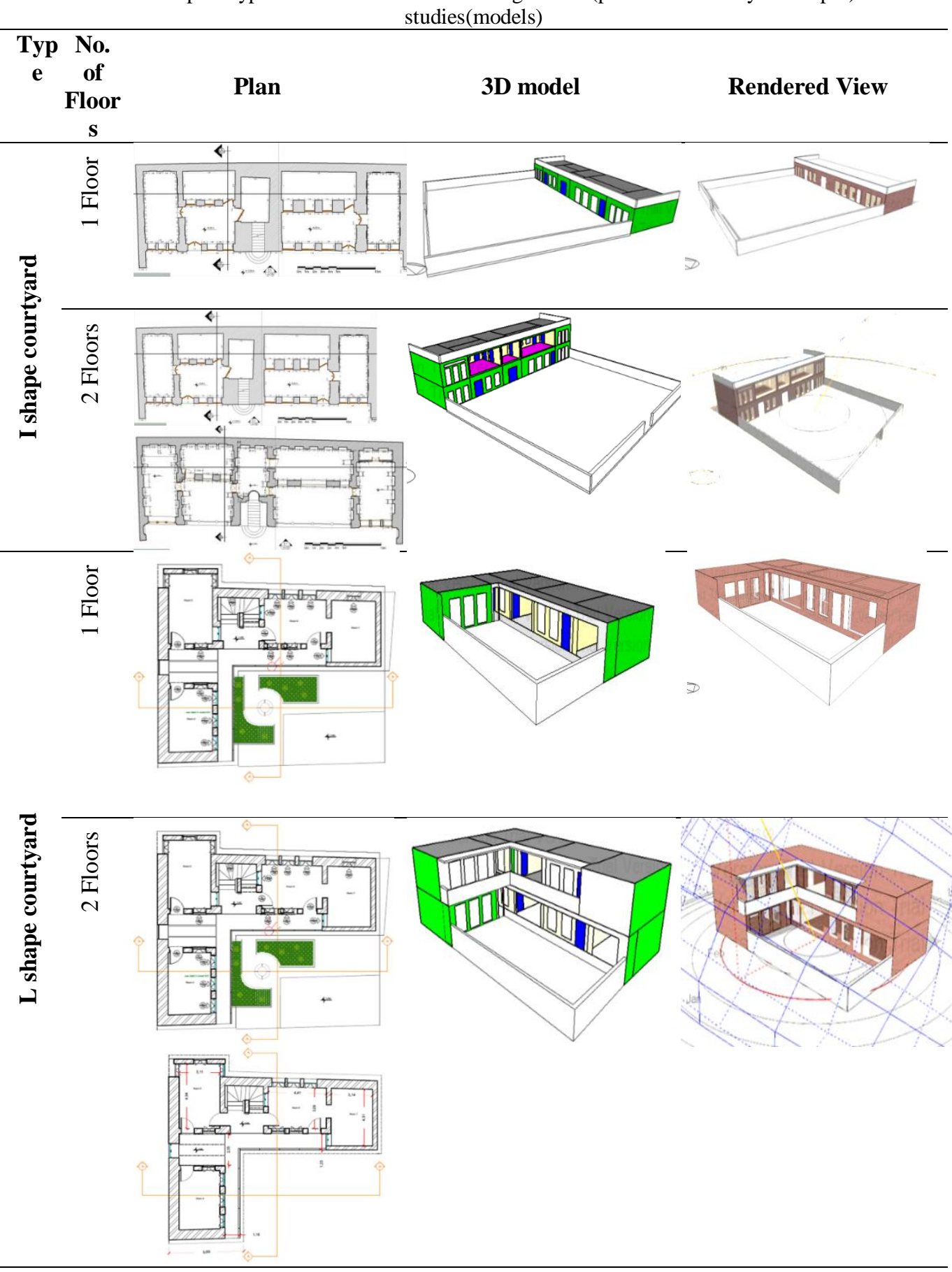


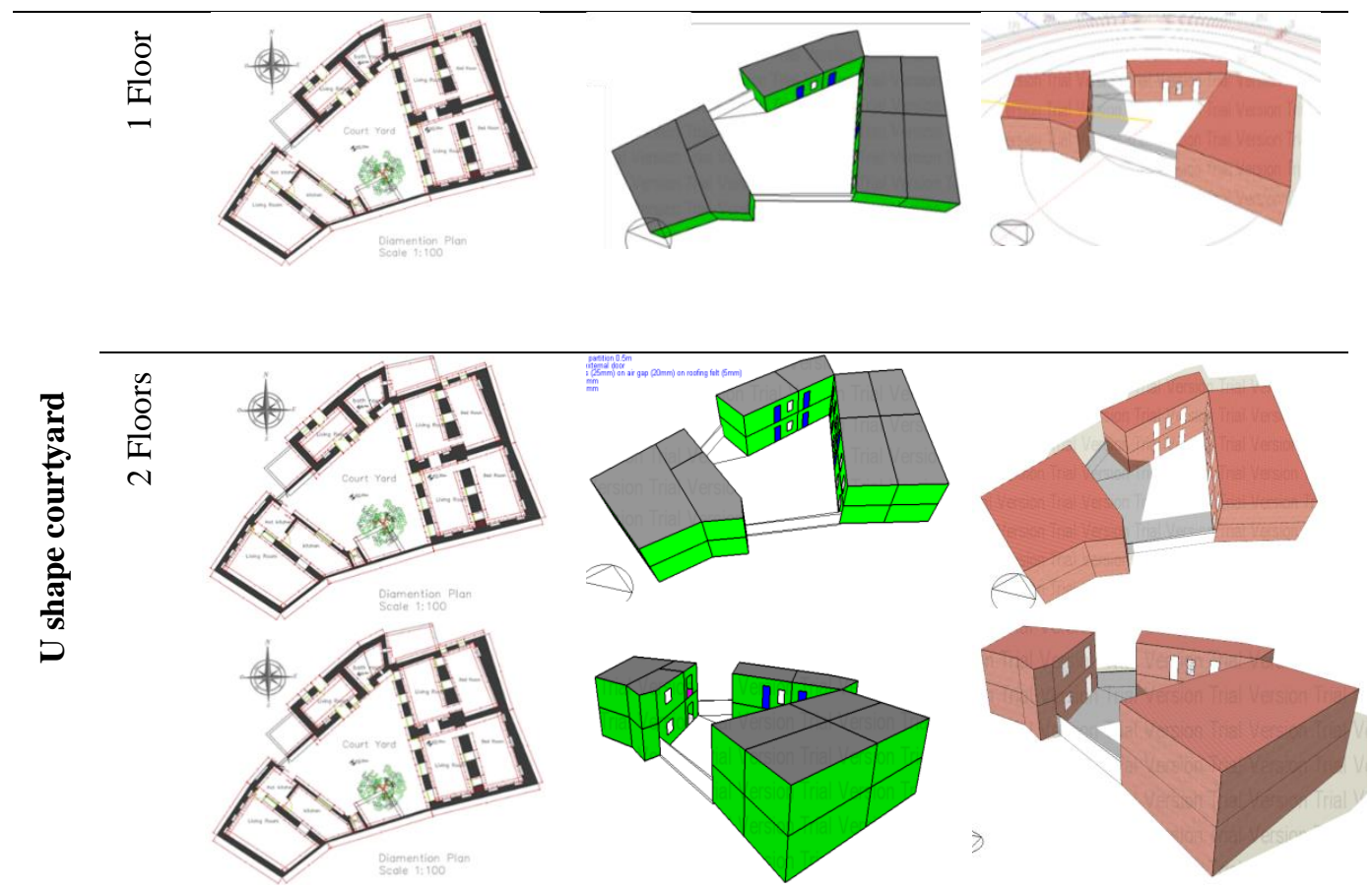

\subsection{Chosen models historical background and construction's description}

The selected types of residential buildings studied in this paper were built more than 100 years ago, and the most common building materials used in the city of Sulaimani were (brick or stone) for the walls, (wooden structure) for the roof and (hard limestone) as main materials. Moreover, the glazing type is single clear $3 \mathrm{~mm}$ with 5,894 (W/m2-k) U-values.
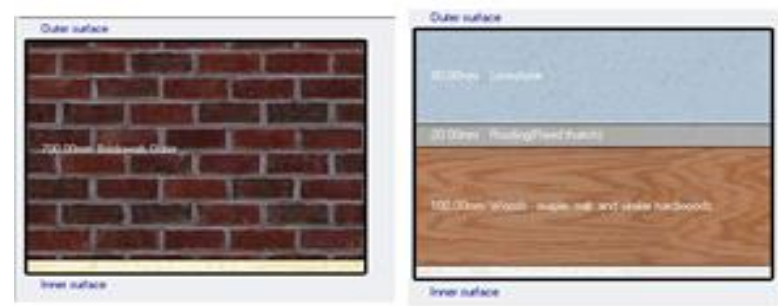

External wall

- 2 layers

- Ovter surface $700 \mathrm{~mm}$ Brick work

- Inner surface $13 \mathrm{~mm}$ Gypsum plastering

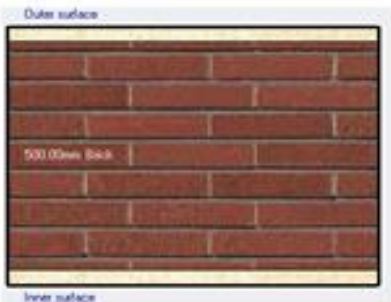

$$
\begin{aligned}
& \text { Internal partition } \\
& \text { Form Ovt to in } \\
& \text { - } 25 \mathrm{~mm} \text { plasterboard } \\
& \text { - } 500 \mathrm{~mm} \text { plasterboard } \\
& \text { - } 25 \mathrm{~mm} \text { plasterboard }
\end{aligned}
$$

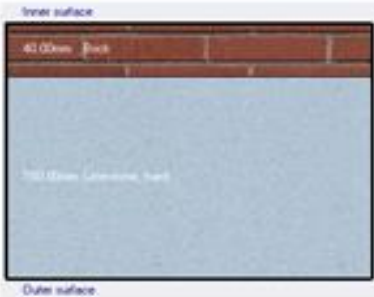

\section{Ground Floor}

- 2 layers

Form Ont to in

- $40 \mathrm{~mm}$ Brick.

- $150 \mathrm{~mm}$ hard limestone

- $1.3 \mathrm{~mm}$ plaster bosed

\section{Glazing / single clear $3 \mathrm{~mm}$} $\mathrm{U}$ value $5.894(\mathrm{~W} / \mathrm{m} 2-\mathrm{k})$

Figure 6: illustrates all building materials construction that was used in all types of studied houses.

(Source: Authors) 


\section{RESULTS and DISCUSSION}

According to the Psychometric chart - climate consultant / Comfort Model ASHRAE Standard 55 and using Sulaimani weather data, the indoor temperature for the comfort zone is between $\left(20^{\circ} \mathrm{C}-26^{\circ} \mathrm{C}\right)$ without using passive or active strategies for cooling and heating. See Figure (7)

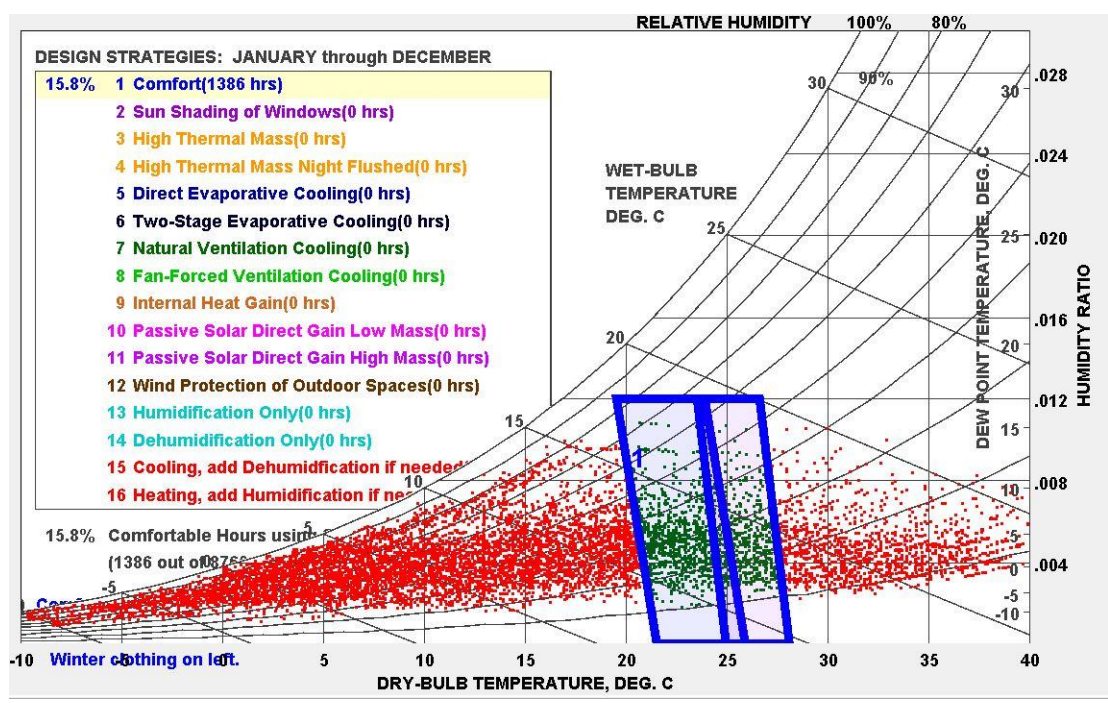

Figure 7: Psychometric chart - Source: Climate Consultant

The result shows that the L-shaped 1-storey yard type had the highest number of days with a comfort range of 146 days without the use of heating and cooling strategies, while the Ushaped 1-storey yard type had the lowest number of comfort days with an indoor temperature between $20^{\circ} \mathrm{C}-26^{\circ} \mathrm{C}$ (Figure 8). Moreover, the best case according to its thermal performance between houses with raised floors is the I-shaped courtyard raised floor, as the number of days these passive and active strategies are needed is less than for other models.



Figure 8: Comparison between the three models in terms of annual thermal comfort days without using any HVAC

However, the difference between the 1-storey U-shaped courtyard and the 2-storey U-shaped courtyard is only 5 days, 4 of which are in October, when the outdoor temperature regularly reaches $14.34^{\circ} \mathrm{C}, 13.73^{\circ} \mathrm{C}, 14.01^{\circ} \mathrm{C}$ and $15.56^{\circ} \mathrm{C}$ on $8,9,10$ and 11 October and the indoor 
temperature is almost $21^{\circ} \mathrm{C}$ on all these days, as shown in Figure 9. This result confirmed that the effect of adding 1 floor for the U-shaped yard type slightly influences the number of comfort days depending on the indoor temperature and relative humidity.

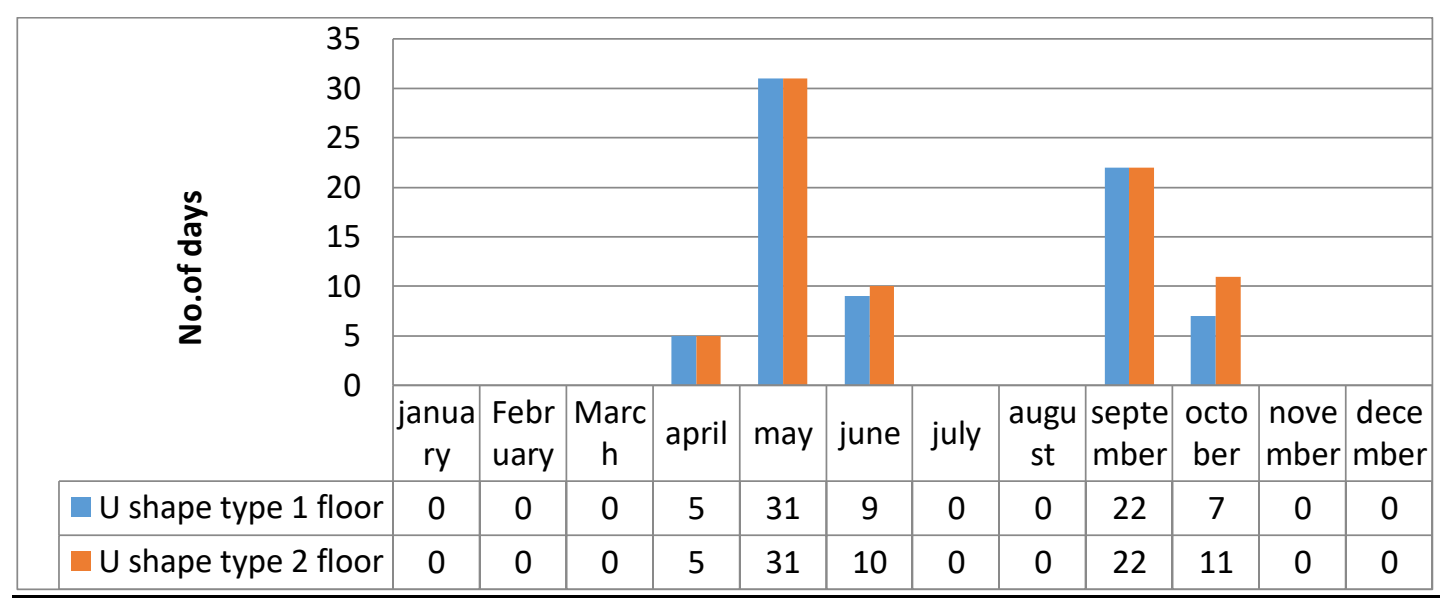

Figure 9: Difference between the U courtyard shape 1 floor and 2 floor monthly comfort days

For the I shape courtyard double floors, which has the second highest percentage of comfort days compared to other types, the comparison with I-shape courtyard 1floor it can be seen that the number of comfort days is higher than I shape courtyard 1floor in (March and April), but there is a significant difference between the number of days in September, as the number of comfort days is 25 days higher for the I-shaped courtyard 1 floors than I shape courtyard 2 floors see Figure (10).

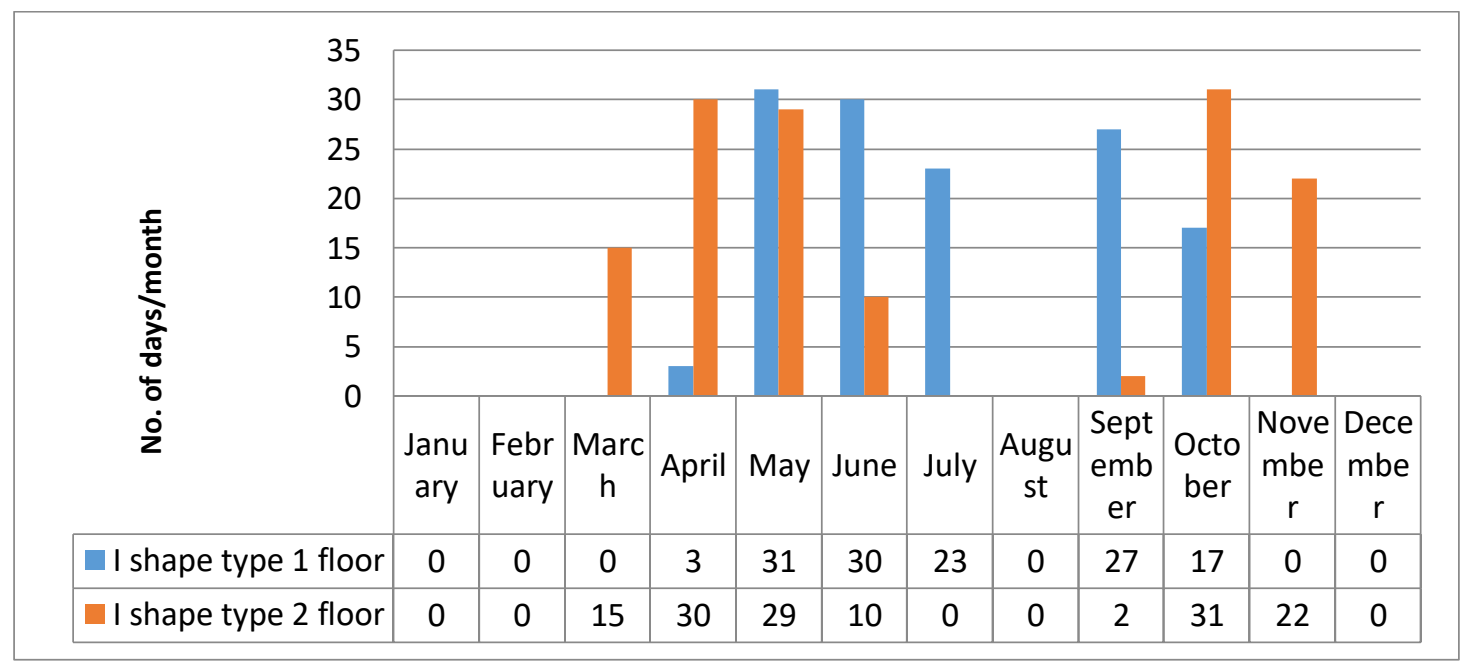

Figure 10: Difference between the I courtyard shape Monthly comfort days

Figure (11) illustrates that in October there is a slight difference in the number of comfort days between the L courtyard shape ( 1 and 2 ) floors and their heating and cooling energy performances are the same in May and November. However, the number of days in September and April for L 1 floors is almost twice as high as for L courtyard shape 2 floors but the biggest differences are in March and June, when the energy performance of L1 floors is better than that of L2 floors, depending on the number of comfort days without heating and cooling 
strategies.

\begin{tabular}{|c|c|c|c|c|c|c|c|c|c|c|c|c|}
\hline \multirow{8}{*}{ 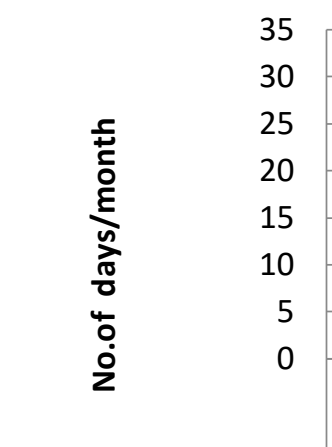 } & & & & & & & & & & & & \\
\hline & & & & & & & & & & & & \\
\hline & & & & & & & & & & & & \\
\hline & & & & & & & & & & & & \\
\hline & & & & & & & & & & & & \\
\hline & & & & & & & & & & & & \\
\hline & & & & & & & & & & & & \\
\hline & Jan. & Feb. & $\begin{array}{c}\text { Mar } \\
\text { ch }\end{array}$ & April & May & June & July & Aug. & Sep. & Oct. & Nov. & Dec. \\
\hline L shape type 1 floor & 0 & 0 & 7 & 30 & 31 & 21 & 0 & 0 & 21 & 31 & 5 & 0 \\
\hline L shape type 2 floor & 0 & 0 & 1 & 14 & 31 & 8 & 0 & 0 & 17 & 29 & 5 & 0 \\
\hline
\end{tabular}

Figure 11: Difference between the L courtyard shape Monthly comfort days

In addition, regarding indoor relative humidity it is described that the acceptable relative humidity in occupied spaces be controlled to less than $65 \%$ to reduce the probability of conditions that could lead to microbial growth. [15]. Therefore, in our work the relative humidity for all the chosen models is examined by simulating all of them with the same software and after finding the relative humidity rate for all comfort days that are determined depending on the indoor temperature, it is shown that the higher rate of relative humidity in all comfort days without using any design strategies is $(62.18 \%)$ for type I shape courtyard 1floor. This means that the relative humidity in all the spaces inside the chosen models are with the acceptable rate for the days that the indoor temperature is between $20^{\circ} \mathrm{C}-26 \mathrm{C}^{\circ}$ without using any strategies for heating and cooling.

\section{CONCLUSION}

A comparison of traditional houses based on the shape of the courtyard and the number of floors (single or doubles) to find out to what extent thermal comfort can be achieved, showing that traditional Kurdish houses in the city of Sulaymaniyah could provide a satisfactory level of climate comfort at different levels.

The study found that the (I-shaped courtyard double floors) and (L-shaped courtyard singlefloor) are the two best courtyard types of traditional houses in the city of Sulaymaniyah. This obvious important result confirms the reason that was hidden beyond the use of large number of these house types in the case study area.

The vernacular architectural approach is the coordination between individuals, buildings and the physical environment to accomplish comfort in energy-efficient buildings.

Thermal and comfort investigations of some traditional houses in the old town of Sulaymaniyah show the great impact of the presence of courtyards as passive cooling techniques. Different design factors, materials, trees and other important factors such as fountain and operating conditions can influence the thermal performance of buildings, but for the purposes of the study they were neutralized.

To improve comfort levels, especially thermal comfort in today's residential buildings, it is recommended to use climate-responsive design strategies and to apply the new technology with more appropriate way.

This study could be seen as a guide for architects and designers, but it is clear that further research and studies on the exact, appropriate use of proportion and size of the courtyard - as a basic element of the design outline - should be followed by architects in their designs. Furthermore, these related questions neutralized, became increasingly essential and could be the subject of future investigation in this area. 


\section{REFERENCES}

[1] A. Rapaport, "House Form and Culture," Englewood Cliffs, NJ, Prentice-Hall, 1969, pp. 7-8.

[2] H. Coch, "Chapter 4--Bioclimatism in vernacular architecture," Renewable and sustainable energy reviews, Elsevier, vol. 2(1-2), pp. 67-68, p.71, June 1998.

[3] P. Oliver, Encyclopedia of Vernacular Architecture of the world, Cambridge: Cambridge University Press, 1997.

[4] H. Glassie, "Architects, Vernacular traditions, and society," Traditional dwellings and settelments review Vol.1, No.2, pp. 9-21, 1990.

[5] P. Sassi, Strategies for Sustainable Architecture, Oxon: Taylor \& Francis, 2006.

[6] B. Ramezani, F. Maghsodi and M. Shafegati, "Assessing and Feasibility of Climatic Comfort in Bandar-e Anzali by effective temperature model and evans," International Journal of Agriculture and Crop Sciences, pp. 6(12), 825-832, 2013.

[7] M. Kasmaii, Climate and Architecture, Tehran: Iran housing investing company, 2008, p. 210.

[8] V. Ghobadian, M. Mahdavi and L. Watson Donald, Climatic Design of Theoretical and Implemental Principles of Energy Application in Buildings, Tehran: Tehran University, 2013.

[9] K. Rabah, "Development of energy-efficient passive solar building design in Nicosia Cyprus," Renewable Energy, Elsevier, vol. 30(6), pp. 937-956, 2005.

[10] D. Alterman, E. Adrian, B. Moghtaderi and C. Zhang, "Contribution of thermal resistance and thermal mass to the energy demand of walling systems," Mauerwerk European Journal of Masonry volume 19, issue (1), pp. 64-73 /doi/10.1002/dama.v19.1/issuetoc, 2015.

[11] D. Alterman, T. Moffiet, S. Hands, A. Page, C. Luo and B. Moghtaderi, "A concept for a potential metric to characterise the dynamic thermal performance of walls," Energy and Buildings, Volume 54, pp. 56-60 https://doi.org/10.1016/j.enbuild.2012.08.006, 2012.

[12] O. Rakoto-Joseph, F. Garde, M. David, L. Adelard and Z. A. Randriamanantany, "Development of climatic zones and passive solar design in Madagascar," Energy Conversion and managment, Volume 50, Issue 4, pp. 1004-1010 https://doi.org/10.1016/j.enconman.2008.12.011, 2009.

[13] A. Ahmed Qader, "Energy Performance of Courtyard and Atrium in Different Climates," Nottingham, 2013.

[14] DateAndTime.Info, "Data and Time.Info," 2011. [Online]. Available: https://dateandtime.info/citycoordinates.php?id=98463. [Accessed 11 April 2020].

[15] A. S. Committee, Ventilation for Acceptable Indoor Air Quality, ASHRAE, 2016.

[16] M. Saligheh, "Modeling housing compatible with climate for Chabahar," Development and Geography Journal 8, no.12, pp. 66-78, 2004.

[17] M. Razjooyan, The comfort by Architecture Consistent with the climate, Tehran: Shahid Beheshti University Pulication, 1988.

[18] R. Soleymanpour, N. Parsaee and M. Banaei, "Climate comfort comparison of vernacular and Contemporary Hoses of Iran," in Asian conference on Environmnet - Behaviour Studies, Tehran, 2015.

[19] M. Milne, Liggett R, Benson A, Bhattacharya Y. Additions to a design tool for visualizing the energy implications of California's climates. Berkeley, California: UC 
Energy Institute; 2009

[20] DesignBuilder 2019. DesignBuilder software 1td.v.5.5.2.3. Available at https://designbuilder.co.uk/. Accessed Dec 2018.

\section{Index}

All three model's data saved from the DesignBuilder software

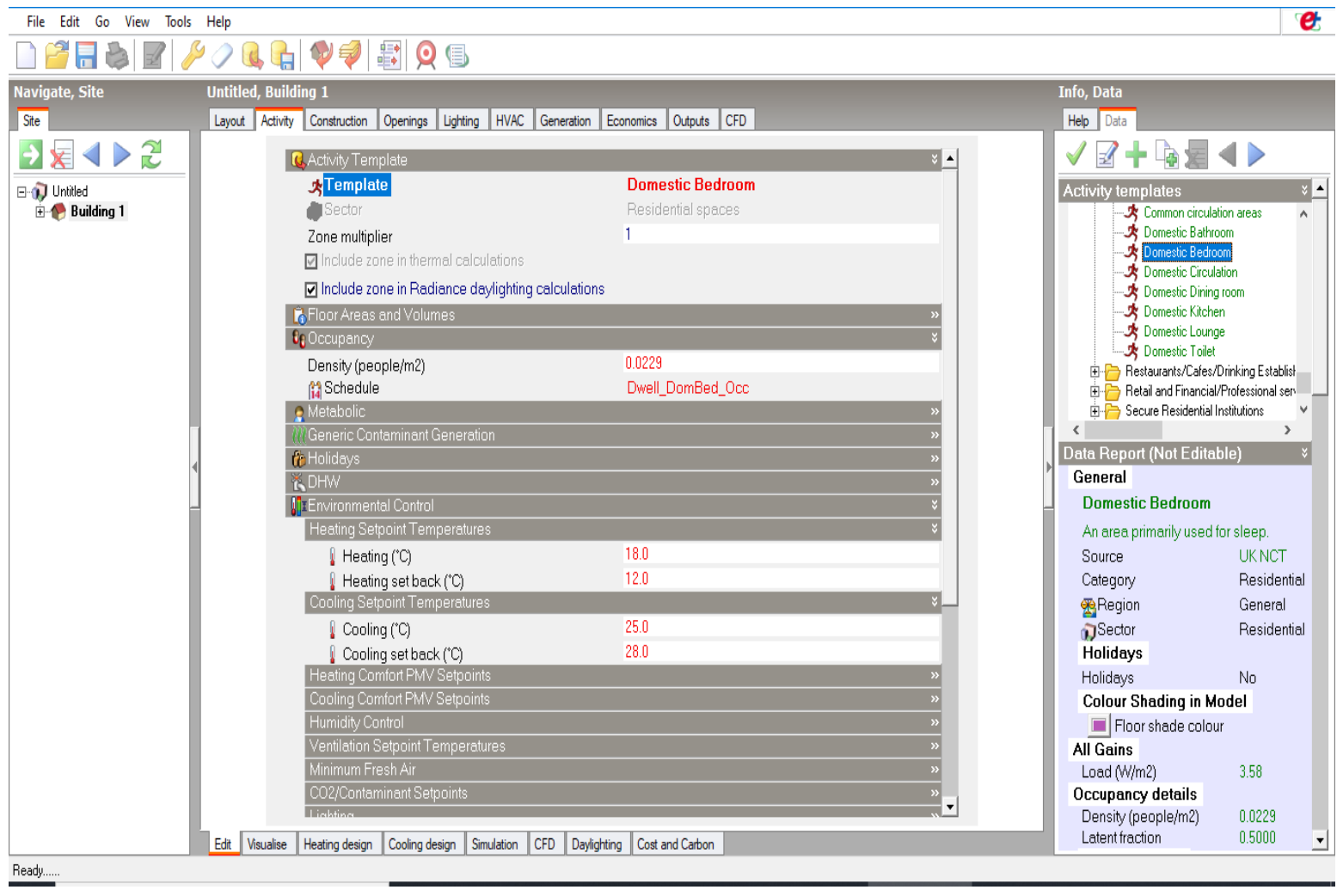

I shape courtyard model data 


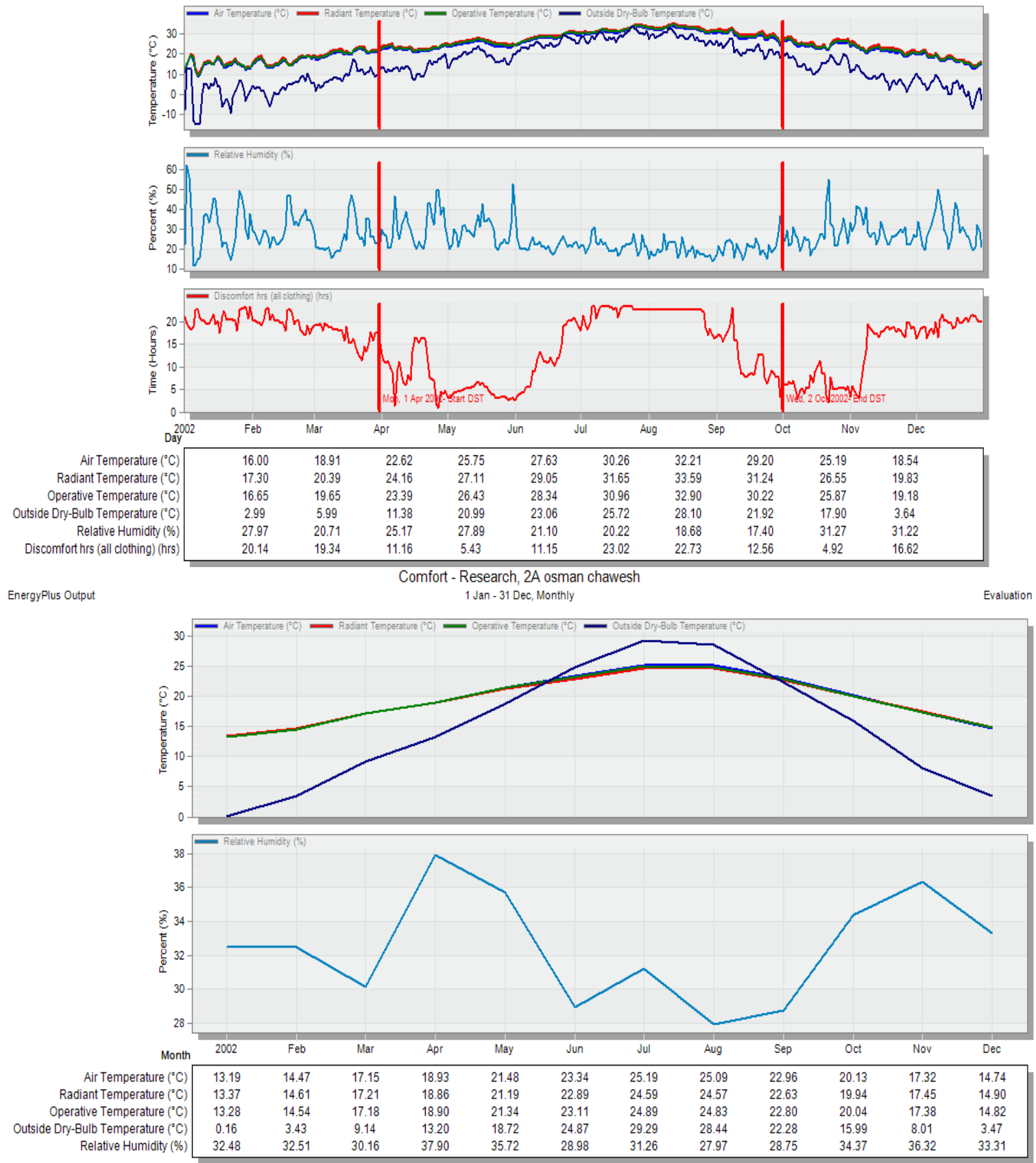




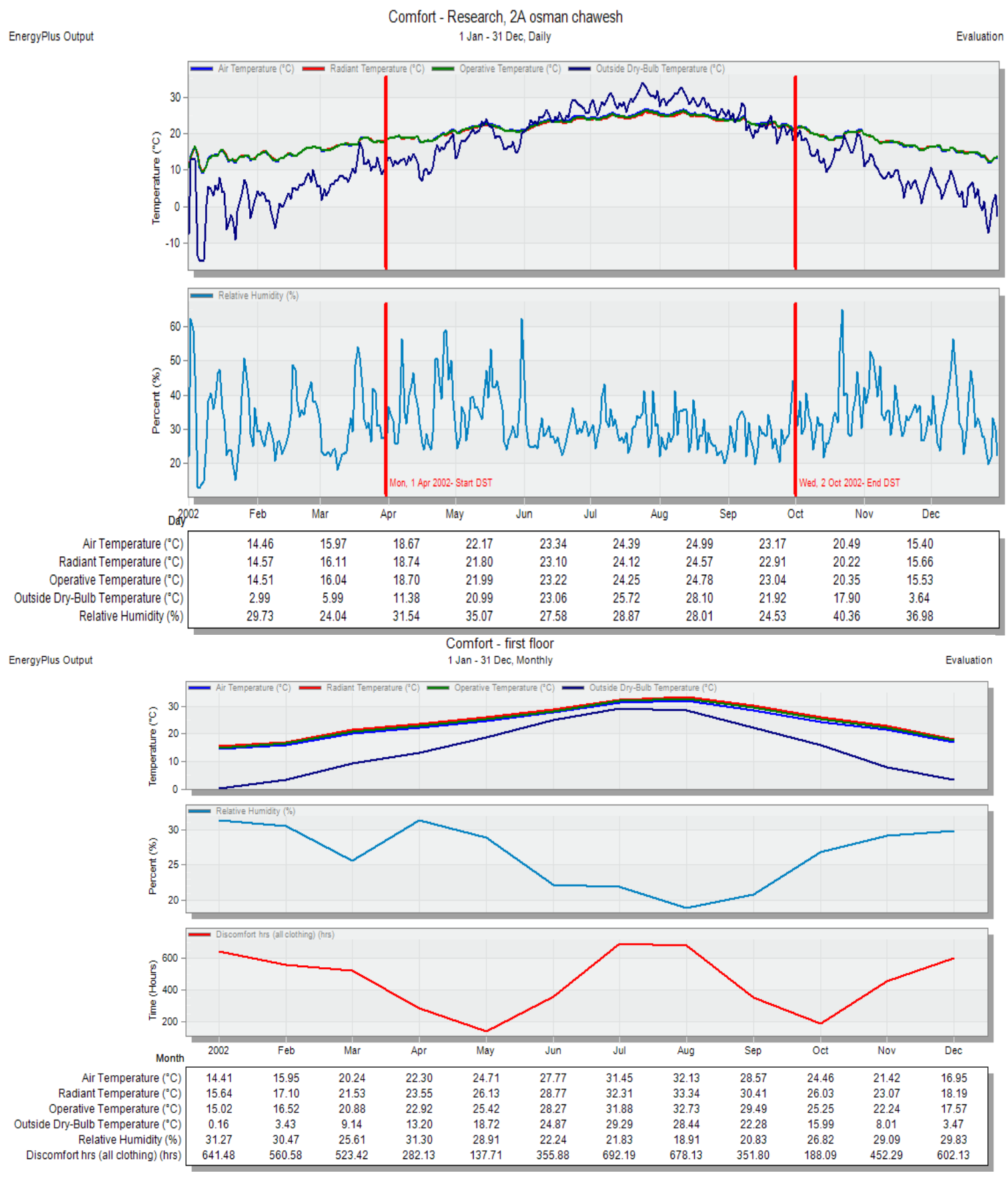

U shape courtyard model comfort data: 


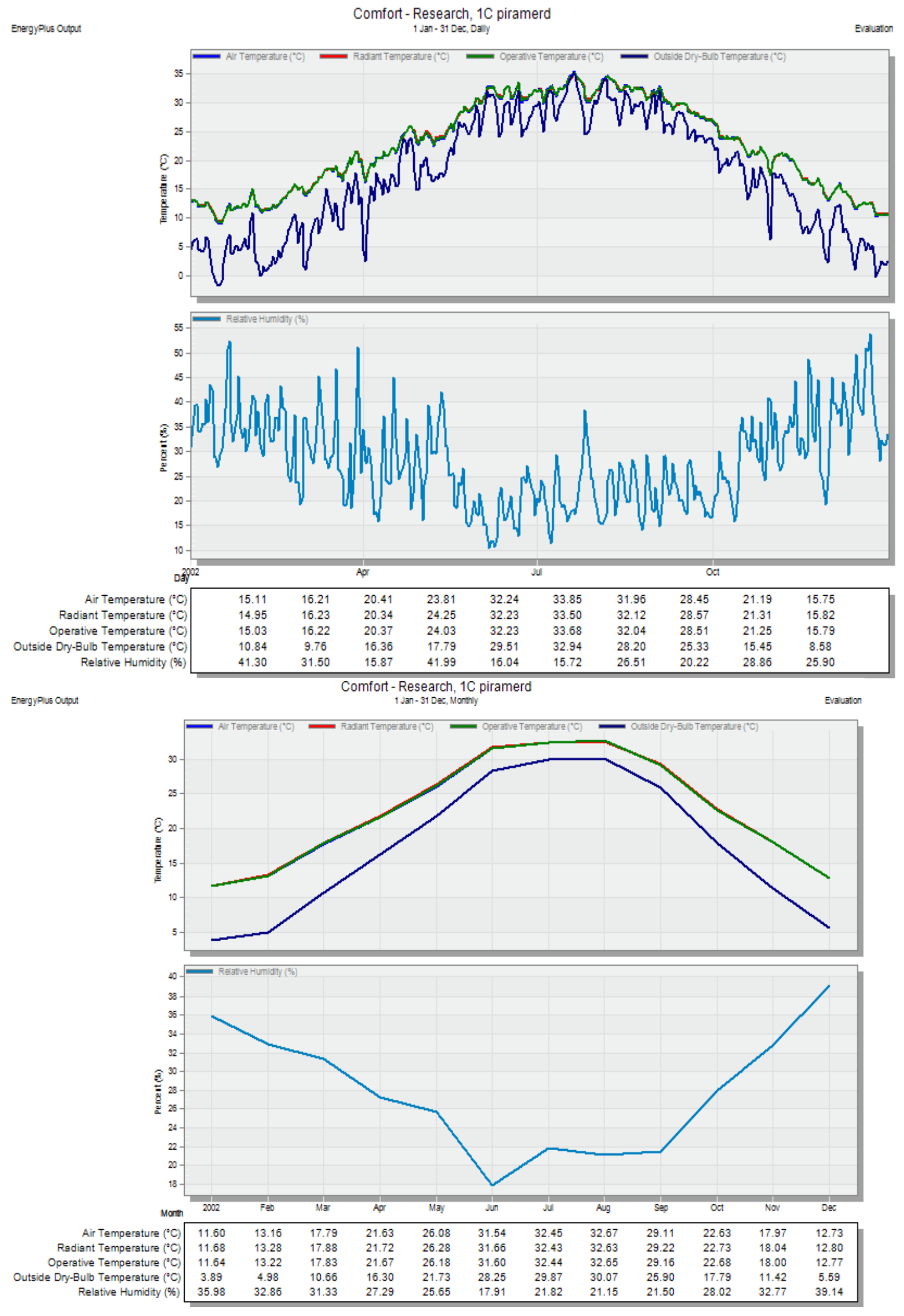

Kurdistan Journal of Applied Research | Volume 5 - Issue 1 - June 2020 | 252 


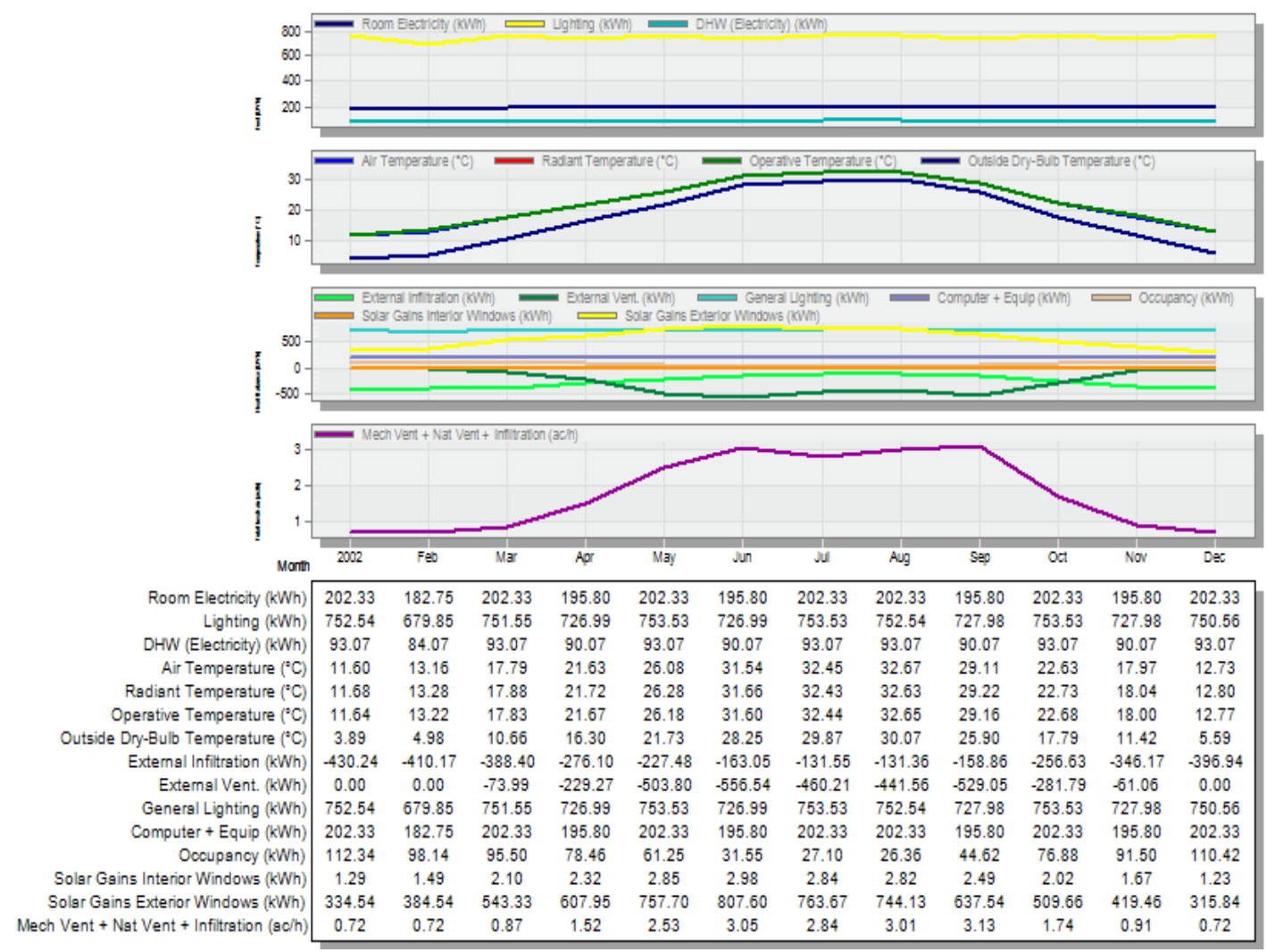

L shape courtyard model thermal data:

EnergyPlus Output

Comfort - Research, Ali baba shex 1 Jan - 31 Dec, Monthly

Evaluation

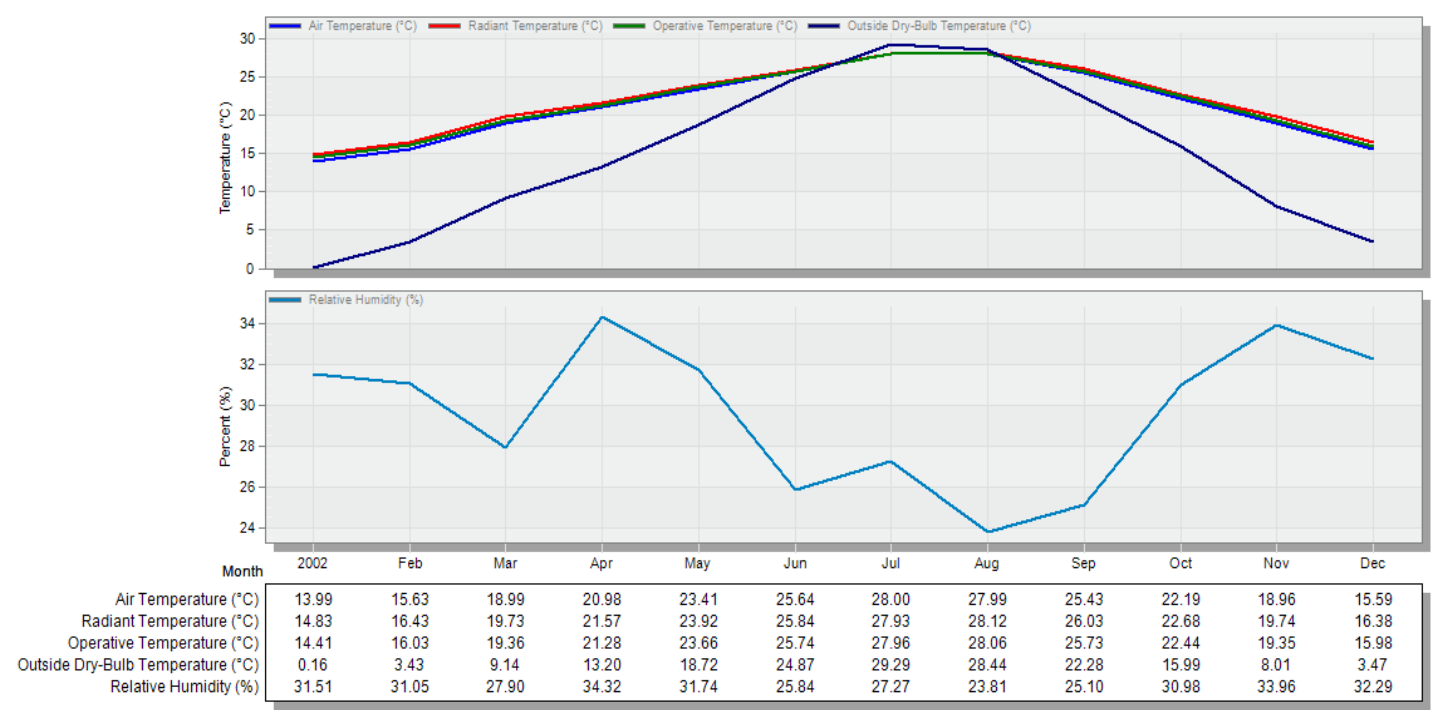




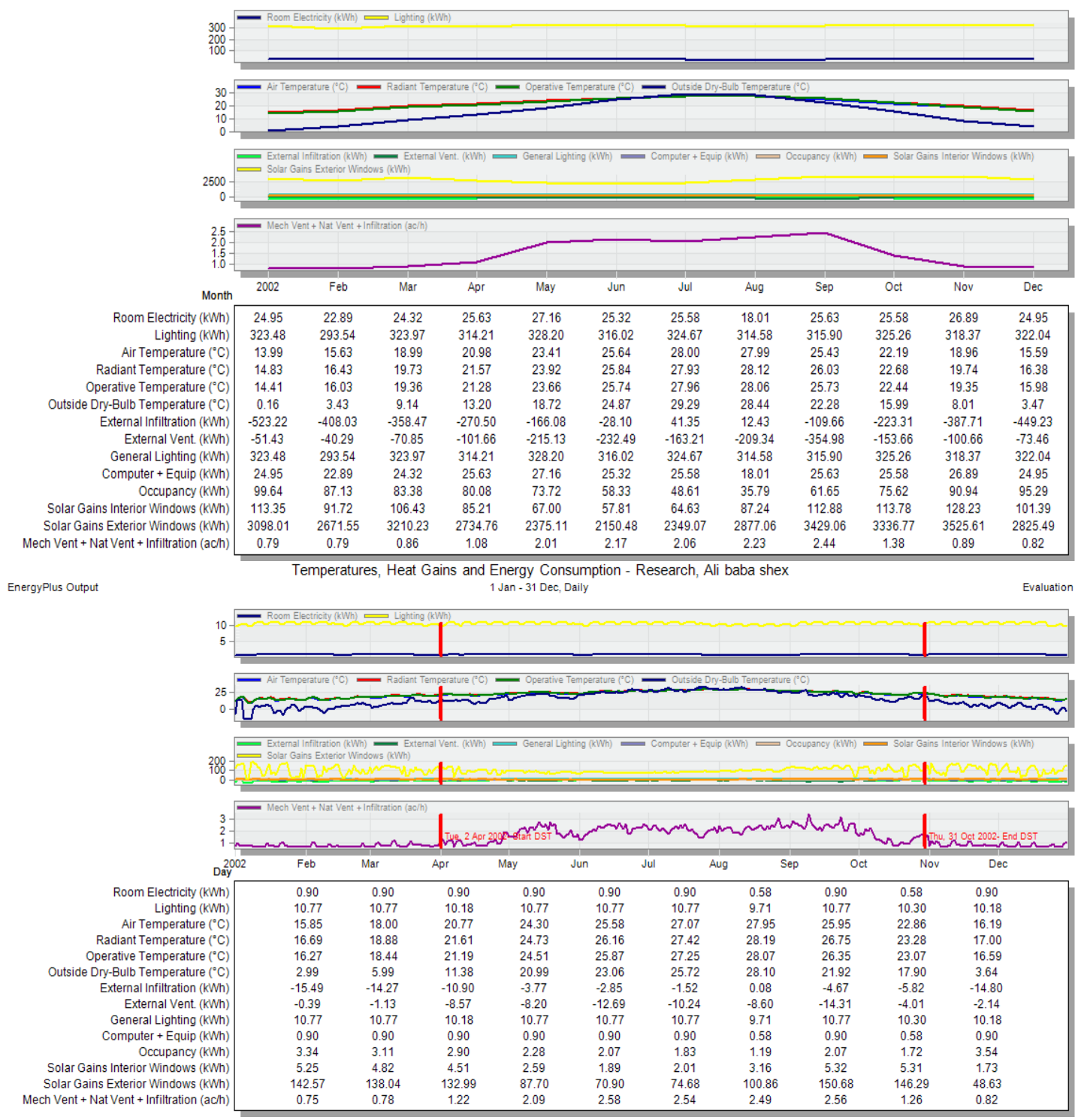




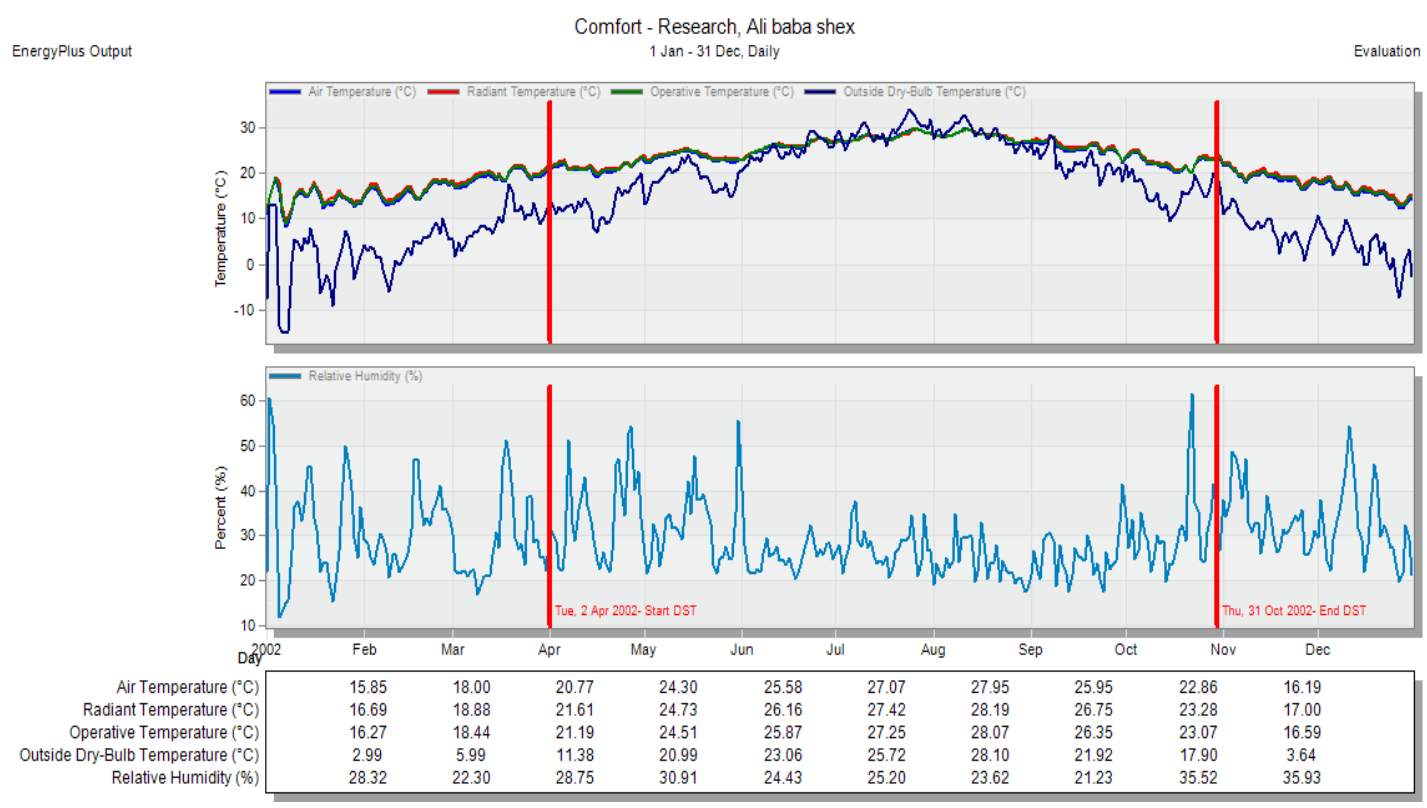




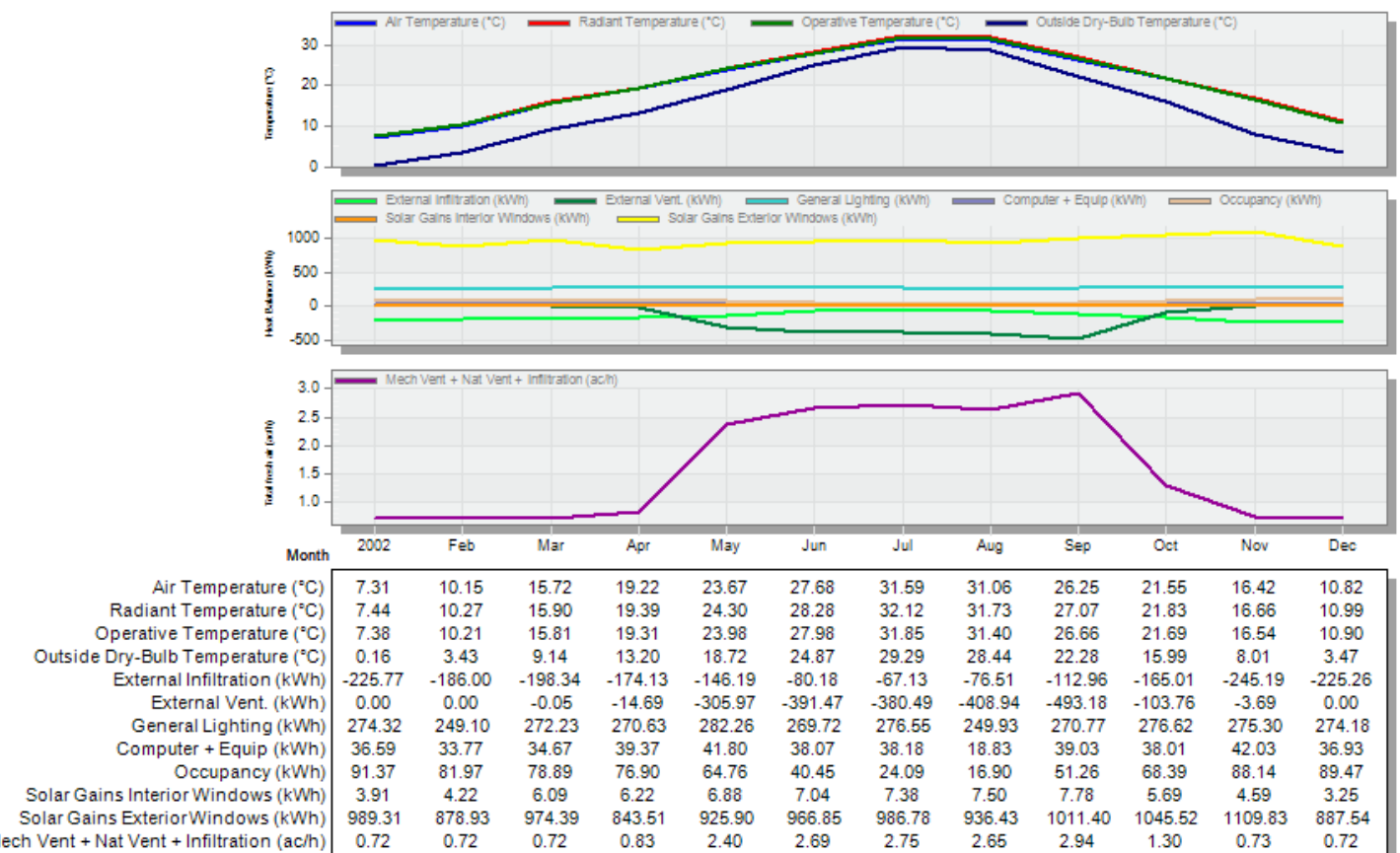

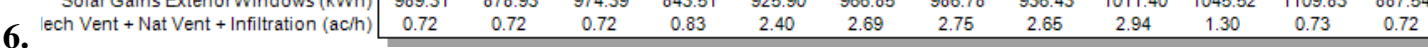

EnergyPlus Output $\quad$ Temperatures, Heat Gains and Energy Consumption - Research, Ali baba shex 1 Jan - 31 Dec, Monthly

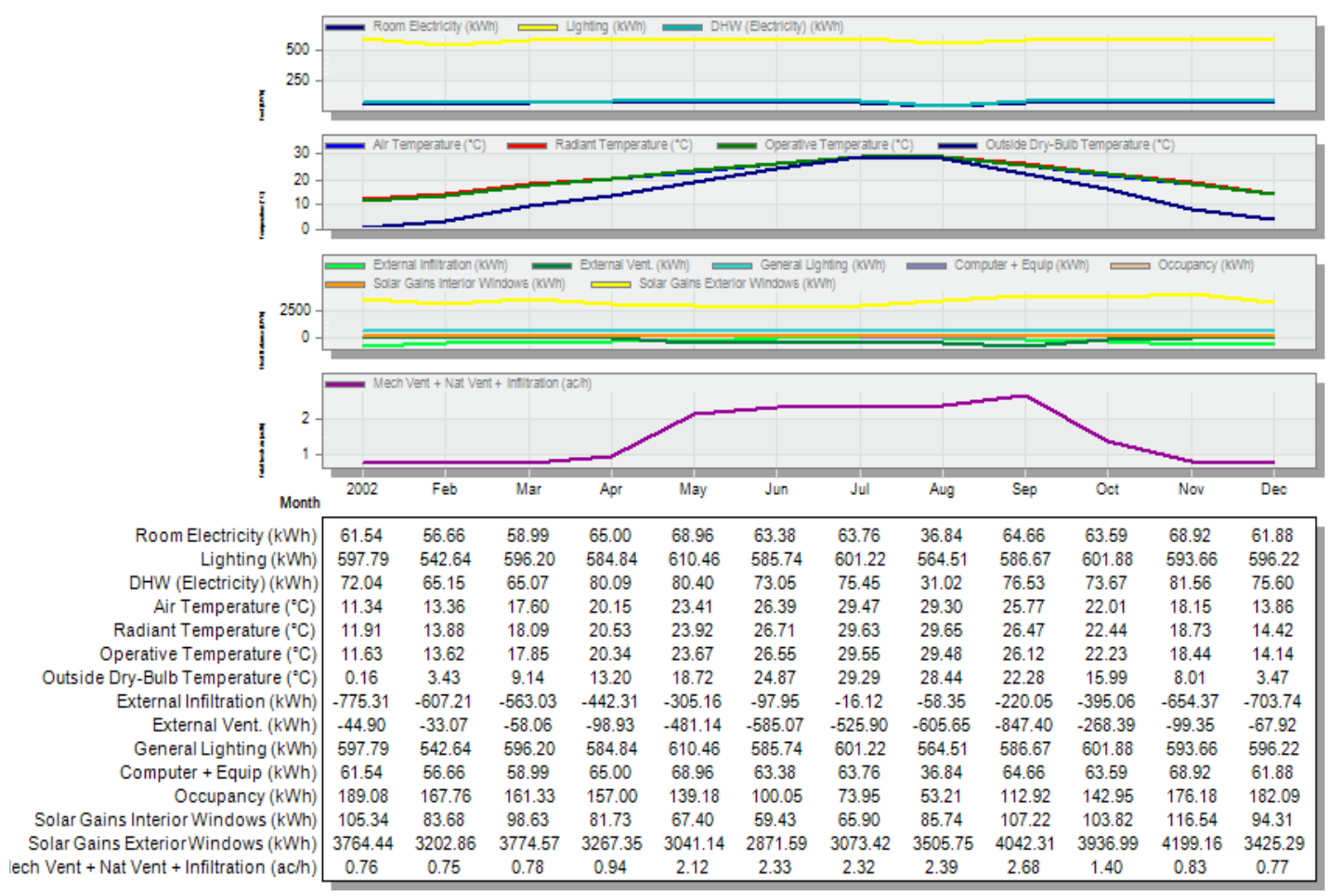




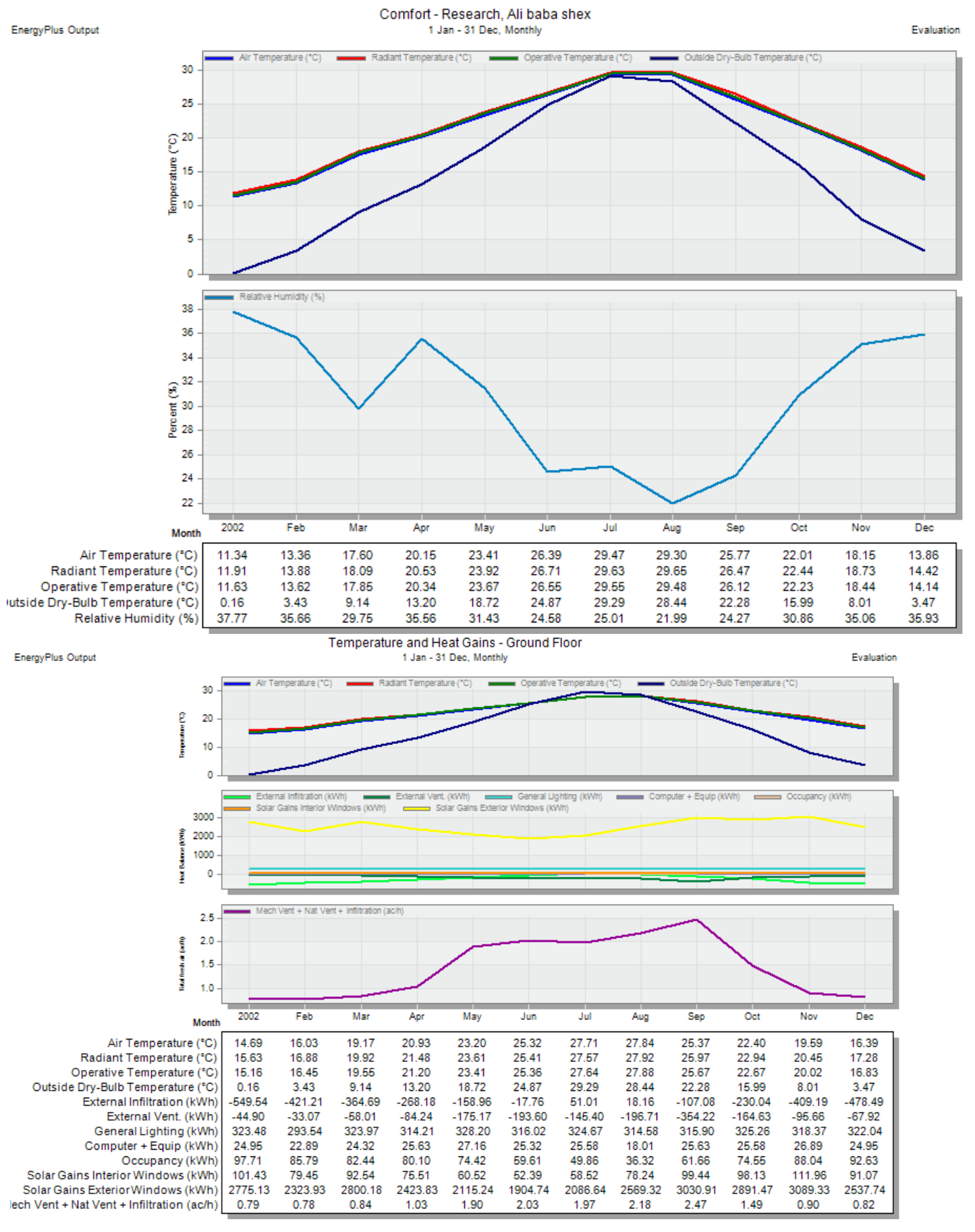

